\title{
A study to compare the pain, discomfort and tiredness between straight stick and single-incision laparoscopic surgery: an in vitro study
}

\author{
Debjani Mukhopadhyay ${ }^{1} \cdot$ Thomas E. J. Ind $^{2,3}$
}

Received: 3 December 2014 / Accepted: 25 March 2015 /Published online: 11 April 2015

(C) Springer-Verlag Berlin Heidelberg 2015

\begin{abstract}
This study compares pain and tiredness experienced by a student and gynaecological surgeons of varying experience between straight sticks (SS) and single-incision laparoscopic surgery (SILS) in vitro. Data was collected prospectively with randomization of the mode sequence. Participants from two hospitals performed identical exercise of cutting circles using SS and SILS in vitro. Questionnaires (Borg CR10 scale scores) were completed at 0,30 and $60 \mathrm{~min}$, respectively. Wilcoxon's signed ranked tests were performed on matched pairs of SS and SILS on the number of circles cut and the mistakes between 0-30 and 30-60 min, respectively. There were significant differences between the two groups at $30 \mathrm{~min}$ in arm discomfort, hand and finger discomfort, shoulder girdle tiredness, arm tiredness and most significantly in wrist discomfort with a matched median difference of 1.83 , confidence interval (CI) 1.00 to 2.67 and $P=0.003$. At $60 \mathrm{~min}$, the significant differences between the two groups were in shoulder girdle pain, arm discomfort, hand and finger discomfort, neck tiredness, wrist tiredness, and hand and finger tiredness and the most significant was wrist discomfort with a matched median difference of 1.75 , CI 0.50 to 3.25 and $P=$ 0.011 . SS causes less tiredness and discomfort in an in vitro setting than with SILS.
\end{abstract}

Debjani Mukhopadhyay

debjani_2008@yahoo.com

1 The Department of Gynaecology and Obstetrics, Ipswich Hospital NHS Trust, Heath Road, Ipswich, Suffolk IP4 5PD, UK

2 The Department of Gynaecological Oncology, St. George's Hospital NHS Trust, Blackshaw Road, London SW17 0QT, UK

3 The Department of Gynaecological Oncology, The Royal Marsden Hospital, Fulham Road, London SW3 6JJ, UK
Keywords Laparoscopy · In vitro training · Single port · Straight stick · Pain score $\cdot$ Fatigue score

\section{Introduction}

There are increasing numbers of complex operations performed laparoscopically [17]. Laparoscopic surgery reduces hospital stay and time to return to normal activity. However, it is also associated with prolonged operating times compared to open surgery which may challenge the surgeon's mental and physical stamina [8]. Single-incision laparoscopic surgery (SILS) has been advocated for gynaecological and other laparoscopic procedures $[17,20]$. There is a direct co-relation between sustained low-level muscular activity and musculoskeletal pain in turn affecting the surgeon's efficiency [16]. Therefore, we have investigated the difference in discomfort, pain and tiredness between SILS and straight stick (SS) in vitro.

\section{Methods}

Ten subjects with varying grades of experience participated. This included one medical student, three junior registrars, one senior registrar, two sub-specialty fellows in gynaecological oncology and three consultants (Table 1). One of the participants, who was a junior registrar, completed only one of the exercises and was excluded from the analysis.

Each participant performed an identical exercise with both SILS and SS. The first mode performed was determined by the flip of a coin. The exercise consisted of cutting out a piece of gauze between two circles of 5 and $3.5 \mathrm{~cm}$ diameter [18]. Templates of the circles were printed with a rubber ink stamp on gauze. Borg CR10 scale was completed prior to 
commencing the exercise [4]. The circles were excised in an in vitro training set, using a grasper (Endo Grasp ${ }^{\mathrm{TM}}$ single use instrument Covidien, MA, USA) and scissors (Endo Shears ${ }^{\mathrm{TM}}$ laparoscopic scissors, Covidien, MA, USA) appropriate for SS. The grasper (Autosuture Roticulator ${ }^{\mathrm{TM}}$ Endo Dissect, Covidien, MA, USA) and scissors (Autosuture Roticulator $^{\mathrm{TM}}$ Endo Mini-Shears ${ }^{\mathrm{TM}}$ Covidien, MA, USA) used for the SILS had an extension with a curve that could protrude or retract as per surgeon's choice using a circular knob on the handle. The exercises were performed on a bespoke laparoscopic trainer using the in-built single instrument ports for SS and in-built SILS port.

The instruments used were out of date instruments retrieved from the hospital store. Borg CR10 questionnaires were completed at 30 and $60 \mathrm{~min}$. The number of circles cut were numbered, stacked in sequence and sealed in an envelope with the participant's number. Participants returned on a separate day to do the same exercise using the other mode. The participants also filled out questionnaires at the same intervals as for the first exercise mentioned above.

The data collected included the grade, gender, handedness, hospital, exercise and time of day they did the exercise, the number of circles they cut between 0-30 and 30-60 min and the number of mistakes on each circle they cut. A mistake was defined as a cut in the line marking the inner or outer circles. This was done for both SS and SILS.

In the absence of any data in the literature, a power analysis was not possible and the number of subjects selected in each arm was empirical. The Shapiro-Wilk test for normality showed that some variables significantly differed from a normal distribution. Therefore, variables were expressed as medians with interquartile ranges. The Wilcoxon signed rank test was used to compare SS and SILS matching for each subject.

\section{Results}

Among the participants, six of nine $(66.7 \%)$ were females and three $(33.3 \%)$ were males. One out of nine $(11.1 \%)$ was left-handed, one $(11.1 \%)$ was ambidextrous and seven $(77.8 \%)$ were right-handed (Table 1).

At $30 \mathrm{~min}$, there was no significant difference detected between SS and SILS for 'headaches', 'shoulder girdle pain' and 'general tiredness' (Table 2). In addition, at $30 \mathrm{~min}$, there were significantly less 'neck pain', 'arm discomfort', 'wrist discomfort', 'hand and finger discomfort', 'neck tiredness', 'shoulder girdle tiredness', 'arm tiredness', 'wrist tiredness' and 'hand and finger tiredness' in SS compared to SILS (Table 2).

At $60 \mathrm{~min}$, there was no significant difference detected between SS and SILS for 'headaches', 'neck pain' and 'general tiredness' in SS compared to SILS (Table 2). In addition, at $60 \mathrm{~min}$, there were significantly less 'shoulder girdle pain', 'arm discomfort', 'wrist discomfort', 'hand and finger discomfort', 'neck tiredness', 'shoulder girdle tiredness', 'arm tiredness', 'wrist tiredness' and 'hand and finger tiredness' in SS compared to SILS.

More circles were cut and less mistakes made over the hour-long exercise when using straight stick compared to single incision (Table 3). This has been demonstrated at both 30 and $60 \mathrm{~min}$ for the number of circles completed but only at the first $30 \mathrm{~min}$ for mistakes (Table 3).

\section{Discussion}

The study demonstrates that participants experienced overall less discomfort, pain and tiredness using SS compared to SILS at both 30 and $60 \mathrm{~min}$ into the exercise irrespective of their experience with laparoscopy. There were no differences in 'headaches' and 'general tiredness' between SS and SILS. Also, there were no differences in 'shoulder girdle pain' in the first $30 \mathrm{~min}$ and no differences in 'neck pain' in the second 30 min (Table 2). This in part may be due to low numbers of participants in the study. The participants cut more circles and made fewer mistakes using SS than SILS (Table 3). However, the design was too small to enable an assessment between doctors of different grades.

Table 1 The demographics of participants

\begin{tabular}{|c|c|c|c|c|c|}
\hline Participant & Grade & Gender & Handedness & Hospital & First mode \\
\hline 1 & Medical student & Female & Right & $\mathrm{SGH}$ & SILS \\
\hline 2 & Gynecological oncology consultant & Female & Left & $\mathrm{RMH}$ & SS \\
\hline 3 & Clinical research fellow & Female & Right & $\mathrm{RMH}$ & SS \\
\hline 4 & Gynecological oncology consultant & Male & Right & $\mathrm{RMH}$ & SS \\
\hline 5 & Gynecological oncology sub-specialty trained fellow & Female & Right & $\mathrm{RMH}$ & SILS \\
\hline 6 & Specialist trainee-year 4 & Male & Ambidextrous & $\mathrm{SGH}$ & SILS \\
\hline 7 & Clinical fellow & Female & Right & $\mathrm{SGH}$ & SILS \\
\hline 8 & Specialist trainee-year 3 & Female & Right & $\mathrm{SGH}$ & SILS \\
\hline 9 & Consultant gynecologist & Male & Right & SGH & SS \\
\hline
\end{tabular}


Table 2 Comparison of tiredness and discomfort scores between straight stick and SILS surgery in vitro

\begin{tabular}{|c|c|c|c|c|c|}
\hline & & \multirow{2}{*}{$\begin{array}{l}\text { Straight stick } \\
\text { MoBLS (IQ range) }\end{array}$} & \multirow{2}{*}{$\begin{array}{l}\text { SILS } \\
\text { MoBLS (IQ range) }\end{array}$} & \multicolumn{2}{|c|}{ Matched median difference } \\
\hline & & & & MoBLS (95 \% CI) & Wilcoxon $P$ \\
\hline \multicolumn{6}{|l|}{ Discomfort and pain } \\
\hline \multirow[t]{2}{*}{ Headache } & After $30 \mathrm{~min}$ & $1.00(1.00-1.00)$ & $1.00(1.00-1.20)$ & $\mathrm{NC}$ & ns \\
\hline & After $60 \mathrm{~min}$ & $1.00(1.00-1.00)$ & $1.00(1.00-1.20)$ & $\mathrm{NC}$ & ns \\
\hline \multirow[t]{2}{*}{ Neck pain } & After $30 \mathrm{~min}$ & $1.00(1.00-1.00)$ & $1.50(1.33-2.00)$ & $0.50(0.00$ to 1.00$)$ & 0.0938 \\
\hline & After $60 \mathrm{~min}$ & $1.50(1.00-1.67)$ & $2.00(1.33-3.00)$ & $0.75(-0.17$ to 2.00$)$ & 0.2500 \\
\hline \multirow[t]{2}{*}{ Shoulder girdle pain } & After $30 \mathrm{~min}$ & $1.00(1.00-1.33)$ & $1.50(1.00-2.25)$ & $0.46(-0.25$ to 1.21$)$ & 0.2188 \\
\hline & After $60 \mathrm{~min}$ & $1.60(1.00-2.00)$ & $3.00(2.00-3.50)$ & $1.00(0.00$ to 2.00$)$ & 0.0391 \\
\hline \multirow[t]{2}{*}{ Arm discomfort } & After $30 \mathrm{~min}$ & $1.33(1.00-1.50)$ & $3.00(2.00-3.00)$ & $1.42(0.50$ to 2.25$)$ & 0.0195 \\
\hline & After $60 \mathrm{~min}$ & $1.00(1.00-2.00)$ & $4.00(3.00-4.00)$ & $2.50(0.83$ to 3.25$)$ & 0.0156 \\
\hline \multirow[t]{2}{*}{ Wrist discomfort } & After $30 \mathrm{~min}$ & $1.50(1.00-2.00)$ & $4.00(3.50-4.00)$ & 1.83 (1.00 to 2.67$)$ & 0.0039 \\
\hline & After $60 \mathrm{~min}$ & $2.00(1.50-3.00)$ & $4.00(3.00-5.00)$ & $1.75(0.50$ to 3.25$)$ & 0.0117 \\
\hline \multirow[t]{2}{*}{ Hand and finger discomfort } & After $30 \mathrm{~min}$ & $3.00(2.00-4.00)$ & $4.00(4.00-4.00)$ & $1.50(0.75$ to 2.25$)$ & 0.0078 \\
\hline & After $60 \mathrm{~min}$ & $3.00(3.00-4.00)$ & $5.00(5.00-5.33)$ & $1.75(0.25$ to 3.50$)$ & 0.0391 \\
\hline \multicolumn{6}{|l|}{ Tiredness } \\
\hline \multirow[t]{2}{*}{ General tiredness } & After $30 \mathrm{~min}$ & $1.00(1.00-2.00)$ & $1.33(1.00-3.00)$ & $0.92(-0.17$ to 2.00$)$ & 0.1563 \\
\hline & After $60 \mathrm{~min}$ & $1.50(1.00-2.00)$ & $2.50(1.00-4.00)$ & $1.00(-0.46$ to 2.13$)$ & 0.1484 \\
\hline \multirow[t]{2}{*}{ Neck tiredness } & After $30 \mathrm{~min}$ & $1.00(1.00-1.33)$ & $2.50(1.50-3.00)$ & $1.00(0.33$ to 2.00$)$ & 0.0156 \\
\hline & After $60 \mathrm{~min}$ & $1.50(1.00-2.00)$ & $3.00(2.00-4.00)$ & $1.17(-0.08$ to 2.42$)$ & 0.0781 \\
\hline \multirow[t]{2}{*}{ Shoulder girdle tiredness } & After $30 \mathrm{~min}$ & $1.33(1.00-1.50)$ & $3.67(2.00-4.00)$ & $1.50(0.00$ to 2.75$)$ & 0.0313 \\
\hline & After $60 \mathrm{~min}$ & $1.80(1.00-2.00)$ & $4.00(3.00-4.00)$ & $2.00(0.50$ to 3.00$)$ & 0.0156 \\
\hline \multirow[t]{2}{*}{ Arm tiredness } & After $30 \mathrm{~min}$ & $1.50(1.00-1.67)$ & $3.50(3.00-4.00)$ & $2.17(0.75$ to 2.75$)$ & 0.0078 \\
\hline & After $60 \mathrm{~min}$ & $2.00(2.00-3.00)$ & $4.00(4.00-5.00)$ & $2.00(0.75$ to 3.00$)$ & 0.0117 \\
\hline \multirow[t]{2}{*}{ Wrist tiredness } & After $30 \mathrm{~min}$ & $1.50(1.50-1.67)$ & $4.00(3.00-4.00)$ & $1.75(0.50$ to 3.00$)$ & 0.0117 \\
\hline & After $60 \mathrm{~min}$ & $2.33(1.50-3.00)$ & $5.00(4.00-5.00)$ & 2.25 (1.00 to 3.33$)$ & 0.0039 \\
\hline \multirow[t]{2}{*}{ Hand and finger tiredness } & After $30 \mathrm{~min}$ & $2.00(1.50-3.00)$ & $4.00(4.00-4.50)$ & $2.00(0.75$ to 3.00$)$ & 0.0195 \\
\hline & After $60 \mathrm{~min}$ & $4.00(1.5-4.00)$ & $5.33(4.00-6.00)$ & $2.25(0.50$ to 3.58$)$ & 0.0234 \\
\hline
\end{tabular}

$M o B L S$ multiples of the baseline score at $0 \mathrm{~min}$ after addition of the value 1 to all scores to account for zeros, $I Q$ range interquartile range, $N C$ not calculated as number of non-zero differences less than $4, n s$ not significant

The limitation with the exercise is that it is performed in an in vitro setting. However, in vitro scoring is known to reflect well in real-life surgery, and there are studies that demonstrate there is good correlation with in vivo practice $[12,14]$. It would be interesting to note if there are any differences in the scores as the exercises become more difficult or with more senior groups of participants.

Psychophysical scores have been studied extensively and have been applied implicitly to sports in order to assess physical activity and to optimize training [1]. Borg CR10 scores

Table 3 Comparison of the number of circles completed and number of mistakes per circle between SS and SILS exercises in-vitro

\begin{tabular}{|c|c|c|c|c|}
\hline & SS Circles & SILS Circles & Median matched difference, $N(95 \% \mathrm{CI})$ & Wilcoxon $\mathrm{P}$ \\
\hline & Number completed, $N$ (IQ range) & Number completed, $N$ (IQ range) & & \\
\hline First $30 \mathrm{~min}$ & $11(9-15)$ & $4(3-9)$ & $6.5(5.0$ to 8.0$)$ & 0.0039 \\
\hline Second $30 \mathrm{~min}$ & $12(10-17)$ & $5(4-8)$ & $6.5(4.0$ to 10.0$)$ & 0.0039 \\
\hline \multirow[t]{2}{*}{ Total } & $23(21-34)$ & $8(8-17)$ & $13.0(9.5$ to 17.5$)$ & 0.0039 \\
\hline & Mistakes per circle, $N$ (IQ range) & Mistakes per circle, $N$ (IQ range) & & \\
\hline First $30 \mathrm{~min}$ & $1.28(0.69-1.50)$ & $2.22(1.70-4.00)$ & $1.44(0.31$ to 2.87$)$ & 0.0391 \\
\hline Second $30 \mathrm{~min}$ & $0.56(0.33-2.10)$ & $1.00(0.50-5.00)$ & $0.77(-0.55$ to 2.79$)$ & 0.1289 \\
\hline Total & $0.96(0.52-2.10)$ & $1.59(0.80-4.50)$ & $0.97(0.08$ to 2.65$)$ & 0.0391 \\
\hline
\end{tabular}


have a maximum value 10 and have been used extensively in surgery $[2,10]$. All surgery involves physical as well as mental activity. The port site can pose problems in optimal handling of laparoscopic instruments intra-operatively when the focus is intense. This may result in pain or fatigue owing to sustained muscular contractions, in turn, affecting the surgical ability. The port site contributes significantly to the surgeon's comfort during laparoscopic surgery [12].

The surgeon's experience is thought to influence the type and the time taken for a procedure, although it does not affect postoperative recovery [9]. Endoscopic surgical experience improves with repeated performance of the surgery over a period of time [3, 7, 19]. This study does not assess skills per se, yet experience would influence the psychophysical score. Engelmann et al. showed that breaks during complex laparoscopic surgery reduced psychological stress maintaining efficiency without prolonging operating time [5]. In athletics, Borg CR10 is used to score and plan the methodology of training [15]. This helps to decide the optimal time spent in training as low-level sustained muscular activity results in musculoskeletal pain [16]. Taking these factors into account, it would be possible to have personal scores to modify the ergonomics and understand the time limit for optimal performance, thus prevent future musculoskeletal problems. In laparoscopic surgery, this would help plan the route of surgery aiming to complete it within a personal optimal time frame.

Repetitive intermittent static movements cause muscle fatigue, and this correlates with discomfort scores [11]. A study to predict musculoskeletal discomfort using Borg CR10 scales showed that trunk inclination and handling frequency are the major determinants of musculoskeletal discomfort [13]. Video feedback to the participants may have helped improve the discomfort scores. A systematic review of single-incision laparoscopic colonic surgery gave a cautious conclusion that SILS should be restricted to highly selected group of patients and surgeons [6]. That study concluded that only experienced surgeons should perform SILS surgery, and our data would support this as in in vitro a group of less experienced surgeons had more pain and discomfort using SILS.

\section{Conclusion}

Laparoscopic surgery needs a unique skill set. This study demonstrates that surgeon's pain and tiredness scores are better in SS than SILS. There is need for further research to establish whether there are any differences between SS and SILS with more difficult exercises and in in vivo.

Funding The authors received no funding for this study.

Conflict of interest Debjani Mukhopadhyay and Thomas J. Ind declare they have no conflict of interest.

Informed consent This article does not contain any studies with human or animal subjects performed by the any of the authors.

Authors' contribution Debjani Mukhopadhyay contributed to the collection of data, literature search and drafting the manuscript. Thomas J. Ind conceived the idea, analysed the data, and critically revised and approved the final version for submission.

\section{References}

1. Bajaj P, Graven-Nielsen T, Arendt-Nielsen L (2001) Post-exercise muscle soreness after eccentric exercise: psychophysical effects and implications on mean arterial pressure. Scand J Med Sci Sports 11: 266-273

2. Bertolaccini L, Viti A, Terzi A (2014) Ergon-trial: ergonomic evaluation of single-port access versus three-port access video-assisted thoracic surgery. Surg Endosc. doi:10.1007/s00464-014-4024-6

3. Bock O, Schneider S, Bloomberg J (2001) Conditions for interference versus facilitation during sequential sensorimotor adaptation. Exp Brain Res 138:359-365

4. Borg G (1990) Psychophysical scaling with applications in physical work and the perception of exertion. Scand J Work Environ Health 16(Suppl 1):55-58

5. Engelmann C, Schneider M, Kirschbaum C, Grote G, Dingemann J, Schoof S, Ure BM (2011) Effects of intraoperative breaks on mental and somatic operator fatigue: a randomized clinical trial. Surg Endosc 25:1245-1250. doi:10.1007/s00464-010-1350-1

6. Fung AK-Y, Aly EH (2012) Systematic review of single-incision laparoscopic colonic surgery. Br J Surg 99:1353-1364. doi:10. $1002 /$ bjs. 8834

7. Gallagher AG, Ritter EM, Champion H, Higgins G, Fried MP, Moses G, Smith CD, Satava RM (2005) Virtual reality simulation for the operating room: proficiency-based training as a paradigm shift in surgical skills training. Ann Surg 241:364-372

8. Glinatsis MT, Griffith JP, McMahon MJ (1992) Open versus laparoscopic cholecystectomy: a retrospective comparative study. J Laparoendosc Surg 2:81-86, discussion 87

9. Herrero A, Philippe C, Guillon F, Millat B, Borie F (2013) Does the surgeon's experience influence the outcome of laparoscopic treatment of common bile duct stones? Surg Endosc 27:176-180. doi: $10.1007 / \mathrm{s} 00464-012-2416-\mathrm{Z}$

10. Hubert N, Gilles M, Desbrosses K, Meyer JP, Felblinger J, Hubert J (2013) Ergonomic assessment of the surgeon's physical workload during standard and robotic assisted laparoscopic procedures. Int J Med Robot 9:142-147. doi:10.1002/rcs.1489

11. Iridiastadi H, Nussbaum MA (2006) Muscle fatigue and endurance during repetitive intermittent static efforts: development of prediction models. Ergonomics 49:344-360. doi:10.1080/ 00140130500475666

12. Kobayashi SA, Jamshidi R, O'Sullivan P, Palmer B, Hirose S, Stewart L, Kim EH Bringing the skills laboratory home: an affordable webcam-based personal trainer for developing laparoscopic skills. J Surg Educ 68(2):105-9. doi:10.1016/j.jsurg.2010.09.014. 
13. Kruizinga C, Delleman N, Schellekens J (1998) Prediction of musculoskeletal discomfort in a pick and place task (a pilot study). Int J Occup Saf Ergon 4:271-286

14. McCluney AL, Vassiliou MC, Kaneva PA, Cao J, Stanbridge DD, Feldman LS, Fried GM (2007) FLS simulator performance predicts intraoperative laparoscopic skill. Surg Endosc 21:1991-1995. doi: 10.1007/s00464-007-9451-1

15. Minganti C, Capranica L, Meeusen R, Amici S, Piacentini MF (2010) The validity of sessionrating of perceived exertion method for quantifying training load in teamgym. J Strength Cond Res 24:3063-3068. doi:10.1519/JSC. 0b013e3181cc26b9

16. Østensvik T, Veiersted KB, Nilsen P (2009) A method to quantify frequency and duration of sustained low-level muscle activity as a risk factor for musculoskeletal discomfort. J Electromyogr Kinesiol 19:283-294. doi:10.1016/j.jelekin.2007.07.005
17. Pathiraja P, Tozzi R (2013) Advances in gynaecological oncology surgery. Best Pract Res Clin Obstet Gynaecol 27:415-420. doi:10. 1016/j.bpobgyn.2013.01.002

18. Peters JH, Fried GM, Swanstrom LL, Soper NJ, Sillin LF, Schirmer B, Hoffman K (2004) Development and validation of a comprehensive program of education and assessment of the basic fundamentals of laparoscopic surgery. Surgery 135:21-27. doi:10.1016/ S0039-6060(03)00156-9

19. Verdaasdonk EGG, Stassen LPS, van Wijk RPJ, Dankelman J (2007) The influence of different training schedules on the learning of psychomotor skills for endoscopic surgery. Surg Endosc 21:214219. doi:10.1007/s00464-005-0852-8

20. Yang TX, Chua TC (2013) Single-incision laparoscopic colectomy versus conventional multiport laparoscopic colectomy: a metaanalysis of comparative studies. Int J Colorectal Dis 28:89-101. doi:10.1007/s00384-012-1537-0 